\title{
El Antropoceno/Capitaloceno y sus implicancias ontológico-políticas: escenario de la pandemia actual ${ }^{1}$
}

\section{The Anthropocene/Capitalocene and its ontological-political implications: scenario of the current pandemic}

\author{
VANESSA IVANA MONFRINOTTI LESCURA \\ Becaria doctoral del Consejo Nacional de Investigaciones \\ Científicas y Técnicas de Argentina. \\ vanee.ml@ hotmail.com
}

\begin{abstract}
RESUMEN
El presente artículo vincula el actual escenario de la pandemia con las implicancias ontológico-políticas advertidas en los debates sobre el Antropoceno/Capitaloceno. En este sentido, los recientes análisis ontológicos en relación a la inauguración de una nueva época geológica dan cuenta de la necesidad de responder a la coyuntura de nuestros días desde propuestas epistémico-políticas en la que prime el abandono de la ontología moderna dualista. Se argumenta que pensar el mundo post-pandemia implica analizar críticamente la ontología dominante y contribuir a un desplazamiento ontológico, que posibilite responder a la urgencia de los tiempos mortíferos del Antropoceno/Capitaloceno.
\end{abstract}

Palabras claves: Antropoceno. Capitaloceno. Ontología Dualista. Giro Ontológico. Pandemia.

\begin{abstract}
This article links the scenario of the pandemic with the ontological-political implications analyzed in the debates on the Anthropocene/Capitalocene. In this sense, the recent ontological analyses about the inauguration of a new geological epoch show the need to respond to the current situation from epistemic-political proposals in which the abandonment of modern dualistic ontology prevails. It is argued that thinking about the post-pandemic world involves critically analyzing the dominant ontology and contributing to an ontological shift, which makes it possible to respond to the urgency of the deadly times of the Anthropocene/Capitalocene.
\end{abstract}

Keywords: Anthropocene. Capitalocene. Dualistic Ontology. Ontological turn. Pandemic.

\section{PUNTO DE INFLEXIÓN. EL ANTROPOCENO COMO CONCEPTO EN DISPUTA}

El presente artículo vincula el actual escenario de la pandemia con las implicancias ontológico-políticas advertidas en los debates sobre el Antropoceno/Capitaloceno. En este sentido, los recientes análisis ontológicos en relación a la inauguración de una nueva época geológica, dan cuenta de la necesidad de responder a la coyuntura de nuestros días desde una ontología política en la que prime el abandono de la ontología moderna dualista. Así, en el

\footnotetext{
${ }^{1}$ Artigo recebido em 30.09.2020 e aprovado em 30.10.2020.
} 
Rev. Interd. em Cult.e Soc. (RICS), São Luís, v. 6, n. 2, p. 86-101, jul./dez. 2020

ISSN eletrônico: $2447-6498$

marco de la convocatoria de este dossier, que nos invita a pensar el mundo post-pandemia, advertimos la urgencia de revisar los compromisos ontológicos que sustentan el avance de las fronteras de apropiación de las naturalezas (humanas y no-humanas). Sostenemos que en el mundo post-pandemia los tiempos mortíferos del Antropoceno/Capitaloceno no habrán cesado.

A partir de la popularización del término Antropoceno a principios de este siglo, uno de los tópicos que mayor relevancia adquirió en la discusión ha sido la datación histórica sobre el inicio del Antropoceno, es decir, cuándo comenzó esta época geológica. Cuando tales investigaciones se encuentran orientadas por un interés propio de las Ciencias de la Tierra, como la Geología y la Estratigrafía, se basan en la búsqueda de las marcas empíricas, es decir, las "marcas doradas", que son los indicadores claves en las capas estratigráficas que identifican y separan las eras geológicas. Desde allí, se han propuesto diversos indicadores para el Antropoceno, entre ellos, los residuos nucleares, los plásticos y los huesos de pollo. ${ }^{2}$ Como se verá, este eje en los debates queda al margen cuando se trata de inquirir sobre las causas y consecuencias de la acción humana en términos ético-políticos y ontológicos, interés central para este trabajo.

El consenso de que estamos en una nueva edad geológica, habiendo abandonado el Holoceno, aún no está dado por la totalidad de la comunidad científica, más específicamente por parte de la Comisión Internacional de Estratigrafía. Es sabido que para ello se debe pasar por una infinidad de requisitos propios de la construcción del conocimiento científico. Para ello se creó en el 2009 el Grupo de Trabajo del Antropoceno, dirigido por el geólogo Jan Zalasiewicz, cuya finalidad es compilar las pruebas necesarias para afirmar que estamos ante una marca geológica irreversible. Tal marca refiere a que por primera vez la humanidad, comprendida como un conjunto indivisible, es la fuerza primordial que moldea la Tierra. Afirmación que despierta los oídos en las humanidades.

Mediante una suerte de movimiento conceptual, que trasciende las fronteras de los claustros disciplinares, el término desde sus inicios no tardó en aterrizar en el seno de las Ciencias Sociales y Humanas, expandiendo el horizonte de los debates, sin interesar su confirmación científica. En este sentido, en principio estamos ante dos conceptos de Antropoceno, el geológico y el cultural (TRIESCHLER, 2017), que se acercan a lo que Jason

2 Este último, evaluado recientemente como "clavo de oro" al considerar que será un registro fósil relevante en el futuro, habida cuenta de los índices de consumo y producción industrial actual, de magnitud abismal. 
Rev. Interd. em Cult.e Soc. (RICS), São Luís, v. 6, n. 2, p. 86-101, jul./dez. 2020

ISSN eletrônico: $2447-6498$

Moore, historiador proveniente del marxismo ecológico, llama como Antropoceno Geológico y Antropoceno Popular. Así, desde aquella conferencia en el 2000 impartida por Paul Crutzen, no dejaron de multiplicarse los Antropocenos, en función de las diferentes disciplinas y posicionamientos epistémico-políticos que comenzaron a participar del debate al interior de las humanidades. De este modo, las discusiones acerca de cuándo es el inicio, cuáles son las causas, la distribución de las responsabilidades, las discontinuidades entre la anterior época y la nueva, el término que debería ser adecuado para su designación, entre muchas otras, se han vuelto tópicos comunes en relación a la temática.

De manera predilecta, siguiendo al historiador Dipesh Chakrabarty (2018), el uso del término "Antropoceno" estuvo orientado a dar cuenta de un giro cuantitativo del impacto humano en el planeta, volviendo en segundo plano la consecuente modificación en la periodización geológica. Aunque esto último, no menos importante, siendo que muchas investigaciones y grupos de trabajo están orientados en ese eje. Pero interesa resaltar que lo principal en las primeras consideraciones que Crutzen y Stoermer (2000) realizaron, no era únicamente afirmar la existencia de un nuevo periodo en la historia geológica, sino señalar la profundidad de la huella humana en el planeta, tanto en la tierra, como en la atmósfera y a una escala global. En cierta forma el término Antropoceno (re)emerge ${ }^{3}$ ante la necesidad de nombrar y enfatizar el rol central que la humanidad está teniendo en el Sistema Tierra, en tanto fuerza geológica primordial.

Ahora bien, las investigaciones científicas sobre el alcance geológico de la acción humana revisten inevitables preocupaciones ético-políticas, incluso para aquellos ámbitos epistémicos que no se ocupan de tales cuestiones de manera predilecta. Pareciera ser que, si bien la división de tareas que responde a la episteme moderna ubica de un lado a las ciencias que estudian la "naturaleza" y, del otro, a las que estudian las cuestiones humanas (de tinte ético, político, social, cultural, económico, entre otros), asistimos a una fisura entre las fronteras disciplinares. El nudo problemático, del que el Antropoceno viene a dar nombre pero del que también se ha advertido bajo la noción de "crisis civilizatoria" (BORSANI, 2017), parece exigir un permanente trabajo transdisciplinar.

Por lo dicho, en las diversas narrativas del Antropoceno oscilan dos registros, uno que involucra las mediciones y debates sobre las "marcas doradas" en los sedimentos, así como

3 Hablamos de "reemergencia" en base a los planteos de J. Bellamy Foster, quien realiza una revisión de la genealogía del término Antropoceno. Ver: FOSTER, John Bellamy (2017) "La crisis del Antropoceno" en Sinpermiso. Disponible en: http://www.sinpermiso.info/textos/la-crisis-del-antropoceno. 
Rev. Interd. em Cult. e Soc. (RICS), São Luís, v. 6, n. 2, p. 86-101, jul./dez. 2020

ISSN eletrônico: $2447-6498$

una multiplicidad de gráficos e índices de límites planetarios superados, y otro, el registro que implica el alcance político y ético, ambos se suelen encontrar en los mismos textos indistintamente de la procedencia disciplinar (CHAKRABARTY, 2018). Dicha situación podría comprenderse como la manifestación en el ámbito de la producción de conocimiento de una desestabilización de los dualismos modernos, es decir, la emergencia de eventos y problemas que ya no se pueden resolver en el marco de una ontología dualista, la que ha distribuido los ámbitos de conocimiento y sus respectivos “objetos” de estudio.

Retomando lo anteriormente señalado, habría de un giro cuantitativo en las modificaciones que el hombre viene realizando en el planeta; sin embargo, sostenemos que sería más acorde hablar de cambios cualitativamente urgentes. Con ello, nos referimos a un punto cercano a la inquietud que plantea Philippe Descola (2017) sobre la diferencia entre el proceso de antropización del planeta y el Antropoceno. El filósofo recupera las observaciones de von Humbolt ${ }^{4}$ y su propia experiencia con comunidades en el Amazonas ecuatoriano, para indicar que el ser humano históricamente ha transformado sus entornos para adaptarlos a sus necesidades en una suerte de interacción e interafectación mutua, aumentando la "habitabilidad" progresiva de la superficie del globo. Desde otras tradiciones de pensamiento, como las de ascendencia marxista, también es posible acercarse a perspectivas relativamente similares en relación al vínculo entre el ser humano y su "entorno", como la noción del metabolismo entre el hombre y la naturaleza.

Estos posicionamientos, a riesgo de generalizar, constituyen una manera de pensar en términos relacionales o lógicas relacionales, dado que sostienen que existe una coconstrucción de los territorios por parte de las prácticas humanas y no-humanas, en un quehacer conjunto y continuo. ${ }^{5}$ En este sentido, lo alarmante del Antropoceno es que da cuenta de un tipo de modificación diferente al intercambio y la mutua alteración entre las especies y sus "entornos", es decir, un acontecimiento diferente que pone en riesgo la habitabilidad misma del planeta. La pregunta con la que sintetiza la problemática Descola es “¿cómo hemos empezado un proceso que tendrá como consecuencia que el planeta Tierra, en lugar de ser cada vez más habitable, lo sea menos?” (DESCOLA, 2017, p. 17).

4 Brevemente, Alexander von Humbolt comprendía a la Tierra como un gran organismo vivo, similar a lo que hoy conocemos como la Hipótesis Gaia de James Lovelock.

5 Las ontologías relacionales y su potencialidad en el presente no podrán ser desarrolladas en profundidad en este trabajo, pero sí es una temática que se encuentra vinculada con los problemas sobre ontología política y el colapso civilizatorio actual. 
Rev. Interd. em Cult.e Soc. (RICS), São Luís, v. 6, n. 2, p. 86-101, jul./dez. 2020

ISSN eletrônico: $2447-6498$

La cuestión de la habitabilidad concuerda con lo que Donna Haraway, otra de las voces más relevantes en estos debates, señala sobre la pérdida de refugios y los territorios devastados del Antropoceno. Para ella el punto de inflexión entre el Holoceno y el Antropoceno radica en la eliminación de la mayor parte de los refugios a partir de los cuales diversos grupos de especies (humana y no-humanas) pueden reconstruirse después de eventos extremos.

El refugio como concepto adquiere cada vez mayor relevancia en cuanto a su alcance político, porque da cuenta de una condición necesaria en todo ser vivo, que es la posibilidad de gestión de la vulnerabilidad de la vida misma, la que se encuentra en riesgo hoy. La desaparición de los refugios implica la eliminación de aquellos espacios que son garantes de alimentación, cobijo y colectivización de relaciones entre especies. Esto es lo que se encuentra en juego. Si no tenemos dónde resguardarnos, habitar y proyectarnos, estamos en un presente sin porvenir. Un aspecto distintivo de dicha noción es que no refiere a un universo exclusivamente humano, aplica a personas humanas y no-humanas. Se proyecta un aumento de refugiados climáticos en los próximos años, comprendidos como aquellas personas que han sido desplazadas de sus territorios porque se han tornado inhabitables debido a condiciones climáticas extremas. A su vez, se habla de refugiados no-humanos, para referir a aquellos animales que son desplazados de sus ecosistemas, por ejemplo a causa de incendios y deforestación. Muchos advierten que los virus de origen zoonóticos, como el de esta pandemia del Covid-19, pero recurrentes en los últimos años (como el SARS, el MERS, las gripe aviar y porcina, etc.), tienen estrecha relación con el permanente avance de prácticas expoliatorias y extractivas en los territorios (RIBEIRO, 2020). Son enfermedades que emergen a partir de la destrucción de los hábitats o refugios de las especies, que se realiza en su mayoría para expandir la frontera agropecuaria industrial (LANDER, 2019).

\section{LA PREGUNTA POR EL ALCANCE POLÍTICO DEL ANTROPOCENO: CRISIS CAPITALOGÉNICA}

Una cuestión que divide aguas al interior del conjunto de estos debates es la denominación apropiada para esta nueva época geológica. Diversos términos se han propuesto para responder críticamente a la noción misma de Antropoceno, los que apuntan a diferentes alcances de la temática. La inspección por parte de las humanidades, entonces, condujo a la invención de términos tales como "Capitaloceno", "Necroceno", "Faloceno", 
Rev. Interd. em Cult. e Soc. (RICS), São Luís, v. 6, n. 2, p. 86-101, jul./dez. 2020

ISSN eletrônico: $2447-6498$

"Occidentaloceno", "Tecnoceno", "Plantacionoceno" o "Chthuluceno", entre otros, los que no serán un tema a desarrollar en este trabajo, a excepción del Capitaloceno, pero sirven para señalar la complejidad y apertura de la temática.

Puntualmente, la noción de Capitaloceno emerge desde el pensamiento ecomarxista (Malm, Moore, Vega Cantor y otros) y se distingue del Antropoceno en la respuesta a la pregunta por las responsabilidades de la devastación socio-ambiental actual. El término Antropoceno, señala a la totalidad de la humanidad como responsable, defendiendo la idea de que el cambio climático, el calentamiento global, los daños ambientales, entre otros, son antropogénicos, es decir, originados por los humanos. Dicha postura cuenta cada vez con más consenso por parte de la comunidad científica, sin embargo, esta idea borra los alcances políticos del colapso del sistema bioclimático.

Señalar a los humanos como responsables, ha sido cuestionado por parte de diferentes posicionamientos epistémico-políticos y como así también por movimientos sociales y activismos. Se torna problemática la distribución igualitaria de la responsabilidad histórica por el cambio climático, en un sistema con una marcada desigualdad económica y política. Hablar de cambio climático antropogénico borra el hecho de que estamos ante una era de crisis capitalogénica.

Entonces, el Antropoceno se concentra en la problemática entre Hombre y Naturaleza, manifestando así una ontología basada en la narrativa de la Humanidad siempre haciéndole cosas terribles a la naturaleza para dominarla. Tanto Hombre como Naturaleza consisten en dos abstracciones que han sido tomadas como reales, siguiendo a Moore (2020), por imperios, estados modernizadores y capitalistas para abaratar tanto a las naturalezas humanas como extra-humanas. En otras palabras, la instauración de un pensamiento dualista y jerárquico estuvo en connivencia con la constitución del capitalismo y posibilitó la creencia de que existe una naturaleza ajena a la excepcionalidad de ciertos humanos. Desde la ontología moderna uno de los mecanismos conceptuales (que se ha desplegado en prácticas diversas) ha sido la conformación de un ámbito ontológico autónomo, inanimado e inerte: lo natural. Esta es la ficción por la cual hemos concebido que lo propio de lo humano -sea la cultura, la razón, la civilización, la sociedad- puede existir de manera independiente a los mundos no-humanos. La noción usual de Antropoceno reitera esa ontología, por ejemplo bajo la quimera de la posibilidad de un "buen Antropoceno", en el que el Hombre finalmente a cumplido el sueño moderno, la emancipación de los humanos de los ecosistemas y la posibilidad de control de 
Rev. Interd. em Cult.e Soc. (RICS), São Luís, v. 6, n. 2, p. 86-101, jul./dez. 2020

ISSN eletrônico: $2447-6498$

las dinámicas climáticas. El caso más emblemático es "Un Manifiesto Eco-Modernista" (ASAFU-ADJA et. al., 2015) que profundiza una visión antropocéntrica, al pretender dar una serie de indicaciones de cómo usar los extraordinarios poderes de la humanidad para crear un buen Antropoceno.

Asimismo, en la historia de la modernidad capitalista, la pertenencia a la Humanidad ha sido un privilegio de pocos, es decir, lo humano ha estado restringido a un grupo selecto: el humano como varón, blanco, burgués, heterosexual, europeo, civilizado. Todo lo que no se amoldara a aquella idea de Humanidad, fue asignado como cercano a la Naturaleza, como espacio de la inferioridad ontológica. "Cuando el Antropoceno Popular rechaza nombrar el cambio climático capitalogénico, fracasa en ver que el problema no es Hombre y Naturaleza, sino ciertos hombres comprometidos en la lucrativa dominación y destrucción de la mayoría de los humanos y el resto de la naturaleza" (MOORE, 2020, p. 3).

La noción de Capitaloceno pretende romper con el "aplanamiento antropocéntrico", que señala a la totalidad de la humanidad como culpable de la devastación, y también con el reduccionismo económico. Esto último implica comprender el capitalismo, además de como un sistema económico de infinita acumulación de capital, como una ecología-mundo, lo que acarrea un desplazamiento ontológico hacia un marco posdualista. La propuesta de Moore de la ecología-mundo afirma que el capitalismos es más que un sistema económico o social, es una manera de comprender, construir y organizar aquello que llamamos naturaleza. Es decir, partiendo de allí, se entiende que los "momentos sociales" de la historia están intrínsecamente vinculados con proyectos ambientales dirigidos a la acumulación de capital. Tal noción de capitalismo posee un alcance ontológico y epistemológico, en cuanto nos obliga a desplazarnos de la comprensión del capitalismo separado de la naturaleza y de la escisión economía/ecología. Durante largos cinco siglos el capitalismo ha operado una metamorfosis de la Tierra, por lo que el término Capitaloceno alerta sobre el alcance geológico del modelo civilizatorio actual.

Ante este contexto, comienza a aparecer la necesidad de un desplazamiento ontológico hacia modos relacionales que asuman las naturalezas humanas y extra-humanas en el mismo tejido de la vida. En palabras de Moore, se trataría de la necesidad de una nueva política ontológica: "Creo que estamos viendo el nacimiento de lo que llamaría una nueva política ontológica. [...], creo que es crucial entender qué tipo de formas de hacer política serán necesarias para forjar un proyecto político emancipador y sostenible en el siglo xxi. Esta 
Rev. Interd. em Cult.e Soc. (RICS), São Luís, v. 6, n. 2, p. 86-101, jul./dez. 2020

ISSN eletrônico: $2447-6498$

nueva política ontológica trata fundamentalmente de la elaboración de nuevas concepciones éticas y políticas de lo que es valioso [...]” (MOORE, 2017, p. 110). Así, el planteo de la ecología-mundo es una apuesta ontológica a una forma relacional de comprender las dinámicas entre sociedad y naturaleza.

\section{DERIVAS ONTOLÓGICAS DE LOS DEBATES SOBRE EL ANTROPOCENO/CAPITALOCENO}

La formalización de que estamos en una nueva época geológica por parte de la Comisión Internacional de Estratigráfica de Ciencias Geológicas y su consenso sobre cuál es el clavo de oro, no resulta central a los fines de las Ciencias Sociales y Humanas, puntualmente para las derivas filosóficas que la temática adquirió. En este trabajo, interesa la emergencia de una nueva época geo-histórica en cuanto sus raíces están asociadas a un modo de vida y una ontología específica; asimismo, importa por sus consecuencias en la desestabilización de la misma ontología que la hizo posible. ¿Qué nos condujo hoy a la devastación que pone en peligro la continuidad de la vida humana y no humana? Esta es la pregunta por las raíces ontológicas, las que son inseparables del modelo civilizatorio dominante, el capitalismo moderno-colonial, que han legitimado y habilitado determinadas prácticas, en sentido amplio. La respuesta en la que coinciden diferentes planteos (Escobar, 2016; Borsani, 2014) apunta a señalar la ontología dualista y naturalista de la modernidad occidental. Al revelar su sesgo político hallamos una ontología de la devastación, de la desfuturización y de la separación, entre otras formas de nombrarla, que permanentemente ejerce una desconexión entre los humanos y el mundo, y un avance contra la relacionalidad que sostiene el tejido de la vida.

La política de la ontología se hace patente cuando Descola afirma: "La humanidad en general no originó el Antropoceno, sino un sistema, un modo de vida, una ideología, una manera de darle sentido al mundo 6 y a las cosas, que sedujeron y se extendieron cada vez más y de las cuales es necesario entender sus particularidades si queremos acabar con aquél y cambiar de rumbo para intentar evitar algunas de sus consecuencias más dramáticas" (DESCOLA, 2017, p. 18). En otras palabras, si queremos resistir la devastación del Antropoceno/Capitaloceno y diseñar mundos otros posibles, debemos hacerlo bajo claves no-

$6 \quad$ El resaltado me pertenece. 
Rev. Interd. em Cult. e Soc. (RICS), São Luís, v. 6, n. 2, p. 86-101, jul./dez. 2020

ISSN eletrônico: $2447-6498$

dualistas y compromisos ontológicos con la relacionalidad que nos permitan respuestas acordes a la urgencia.

En este sentido, sostenemos que el Antropoceno ha comenzado a pensarse en términos ontológicos, es decir, el giro ontológico presente en las Ciencias Sociales y Humanas desde hace algunos años, también arribó a este nudo problemático. Desde estos posicionamientos el origen del Antropoceno, importa en cuanto se analiza la imbricación entre el modelo civilizatorio dominante y la ontología que ha asumido. Esto se torna relevante al momento de pensar los futuros posibles, dado que debemos reflexionar bajo qué claves hay que "futurizar", qué modos de hacer comunidad, qué opciones socio-políticas se abren desde el marco de la ontología política, todas ellas inquietudes que están en la base de este trabajo.

Entre el conjunto de las propuestas que se encuentran ejerciendo dicho giro ontológico, interesa nombrar a Escobar, Blaser, Danowski y Viveiros de Castro, Latour, Chakrabarty, Haraway, Moore, entre otres. Todes coinciden en el esfuerzo de pensar en marcos posdualistas y en revisar la ontología moderna, habida cuenta de la crisis actual. Si bien se tratan de diferentes aportes y parten desde disciplinas y posicionamientos epistémicos distintos, coinciden en que las narrativas del Antropoceno, son parte de una crisis más profunda, que viene afectando hace tiempo a la ontología dominante del capitalismo. El Antropoceno/Capitaloceno, en este sentido, se comprende en el marco de un escenario más amplio, como una manifestación de una crisis ontológica, en tanto la relación entre hombre y el mundo, el hombre y la naturaleza, el hombre y el conjunto de los mundos no-humanos, merece una revisión y transmutación urgente. De este modo, coincidimos en que la causa principal del origen del Antropoceno "[...] es el desarrollo, desde algunos siglos atrás, primero en Europa occidental y luego en otras regiones del planeta, de un modo de composición del mundo que llamamos de diversas maneras, según aspectos del sistema que queramos mostrar: capitalismo industrial, revolución termodinámica, Tecnoceno, modernidad o naturalismo." (DESCOLA, 2017, p. 21).

Los alcances ontológicos del acontecimiento del Antropoceno se despliegan en por lo menos tres puntos que quisiéramos señalar, que ponen en evidencia la crisis de los modos de pensamiento dualistas y la imposibilidad de continuar insistiendo en una ruptura ontológica Hombre/Naturaleza. En primer lugar, estamos ante la presencia de un nuevo tipo de "naturaleza" que no responde a los dictados modernos, "la intrusión de Gaia" (STENGERS, 2017). En segundo lugar, la comprensión de la humanidad bajo una nueva dimensión, que es 
Rev. Interd. em Cult.e Soc. (RICS), São Luís, v. 6, n. 2, p. 86-101, jul./dez. 2020

ISSN eletrônico: 2447-6498

la de agente geológico. En tercer lugar, el colapso de ciertos dualismos que han estado en la base de la conformación de la episteme moderna. Resulta necesario aclarar que estos tres puntos están estrechamente entrelazados y co-implicados.

En lo referido al primer punto, la filósofa Isabelle Stengers viene advirtiendo la emergencia de una nueva trascendencia que ya no oficia de escenario estable, regulable y predecible. Es decir, la construcción ontológica de un ámbito externo y despolitizado, la llamada naturaleza, cada vez será más difícil sostenerla. Comprende la intrusión de Gaia como un acontecimiento que nos cuestiona y que es ciego en cuanto a los destrozos que ocasiona. Consiste en un llamado a pensar lo que provocó su intrusión, esa es la clave bajo la cual hay que diseñar las respuestas no solo al Antropoceno, sino también a la pandemia actual. Se trata de una Gaia que no refiere a la Tierra como un organismo vivo con una estabilidad interna, ni a un vínculo de pertenencia con aquello a lo que la modernidad insistió en separarnos. Una Gaia ciega e indiferente, cuya comprensión no es tranquilizadora. "Ya no nos enfrentamos a una naturaleza salvaje y amenazadora, ni con una naturaleza frágil, que hay que proteger, ni con una naturaleza que se puede explotar a voluntad. El caso particular es nuevo. Gaia, la que hace intrusión, no nos pide nada, ni siquiera una respuesta a la pregunta que impone" (STENGERS, 2017, p. 42).

En el 2009 un conjunto de científicos identificaron nueve procesos biofísicos del Sistema Tierra y establecieron límites para cada uno, cuya transgresión implicaría alteraciones irreversibles e insoportables para la vida humana y no-humana en el planeta. Esta serie de procesos poseen una conexión interna, de tal forma que si resulta afectado uno de ellos, los otros corren riesgo, en una suerte de reacción en cadena. Tres de esos procesos ya estarían fuera de la zona de seguridad: la tasa de pérdida de la biodiversidad, la interferencia humana en el ciclo del nitrógeno (modificado para el uso humano, principalmente para fertilizantes) y los cambios climáticos. El concepto de fronteras o límites planetarios ha sido temática recurrente en las revistas que gozan de mayor autoridad en el ámbito científico, Nature y Science $^{7}$. La superación de estos límites, es parte también de una serie de eventos que consisten en la alteración acelerada de ciertos parámetros en aumento: la concentración de $\mathrm{CO}_{2}$ en la atmósfera, la acidificación de los océanos, el derretimiento de los glaciares, las temperaturas medias, la tasa de extinción de especies, entre muchos otros aspectos, que advierten un futuro próximo imprevisible e inimaginable.

$7 \quad$ Sobre estas nueve fronteras, ver: Will Steffen et al. "Planetary boundaries: Guiding human development on a changing planet" en Science, vol 347, n. ${ }^{\circ} 223,2015$. 
Rev. Interd. em Cult.e Soc. (RICS), São Luís, v. 6, n. 2, p. 86-101, jul./dez. 2020

ISSN eletrônico: $2447-6498$

Con cada vez mayor insistencia se alerta la ruptura de un margen de tolerancia, con índices, mediciones, marcas empíricas, parte también del Antropoceno Geológico. Esto es alarmante dado que corremos el riesgo de una respuesta por parte de Gaia, cuyos alcances no pueden evaluarse como justos o injustos, es decir, su agencia no aparece como justiciera, por lo que su reacción bien podría ser excesiva y no distinguir responsables. Una naturaleza que comenzará a tener cada vez mayor agencia en el mundo humano, pero que en gran medida serán intervenciones de carácter incontrolable o impredecible. Es la intrusión de Gaia en el escenario humano, que de manera abrupta llegará a afectar nuestra más íntima cotidianidad. Allí, Danowski y Viveiros de Castro ven un nuevo agente histórico y político.

Esto último se puede ejemplificar con la "aparición” del virus Covid-19, que si bien se venía advirtiendo de su posibilidad hace tiempo, hay algo de lo azaroso e imprevisible con exactitud. Una "reacción" que no se puede calcular, pero que sí es evitable, por eso la respuestas deben ir hacia aquello que lo provocó. El virus no es algo "natural", es un ente semiótico que trama política, historia, economía, alimentación, sistemas de transporte, globalización y mucho más. Ahora debemos lidiar con una nueva presencia: "La intrusión del tipo de trascendencia que yo llamo Gaia hace existir en el seno de nuestras vidas una incógnita mayor, y que ha venido para quedarse. Por otra parte, es lo que tal vez sea lo más difícil de concebir: no existe un porvenir previsible donde ella nos restituya la libertad de ignorar [...]." (STENGERS, 2017, p. 43). El virus que circula actualmente es manifestación de todo ello, un desvío contingente ocasionó que una cepa de coronavirus parara en un organismo humano.

En relación a otro de los alcances ontológicos, cabe referir al hecho de que el hombre en el Antropoceno se ha vuelto un agente geológico primordial. El ser humano abandonó su carácter de simple agente biológico, para asumir una dimensión mayor, la de fuerza geológica. Esto implica comprendernos como una fuerza parecida a la que ha producido la extinción masiva de especies en otros periodos geológicos, pero la diferencia es que somos el primer agente consciente de su accionar. La intromisión del ser humano en la historia geológica, destruye la distinción artificial, basada en la ontología moderna, entre historia natural y humana. ${ }^{8}$ Para las Ciencias de la Tierra, la cronología humana y sus acciones eran insignificantes en comparación con los procesos geológicos. En las diversas narrativas del

8 No obstante, con artificial no se quiere decir irreal, dado que ha sido una distinción que forma parte de una ontología, que además de encontrarse en nuestros discursos y supuestos, también se ha manifestado en prácticas y en la construcción de realidades, instituciones, políticas, economías, etc. 
Rev. Interd. em Cult.e Soc. (RICS), São Luís, v. 6, n. 2, p. 86-101, jul./dez. 2020

ISSN eletrônico: $2447-6498$

Antropoceno, lo humano aparece bajo nuevas dimensiones y conceptualizaciones que requerirán mayor detenimiento.

Por lo dicho, el colapso de muchas de las divisiones modernas se hace inminente, dada la colisión de los seres humanos con la Tierra. En otros términos, "la terrorífica comunicación de lo geopolítico con lo geofísico, contribuye de manera decisiva al desmoronamiento de la distinción que era fundamental para la episteme moderna: la distinción entre los órdenes cosmológico y antropológico [...]" (DANOWSKI Y VIVEIROS DE CASTRO, 2019, p. 43). Ambos ámbitos separados desde el siglo XVII, en una discontinuidad de naturalezas y de escala. El tiempo geológico y el tiempo histórico humano, la historia natural y la historia humana, todas distinciones humanistas que colapsan y que tornan insuficientes los marcos epistémicos tradicionales (CHAKRABARTY, 2009). La naturaleza, como espacio geográfico, escenario del devenir histórico humano, "aparentemente intemporal telón de fondo" que los historiadores han asumido, se ve hoy irrumpido por la posibilidad de que las acciones humanas afecten de manera significativa a ese "fondo". Así también, Gaia no será ajena a la historia humana y sus devenires socio-políticos.

\section{EL MUNDO POST-PANDEMIA Y LA URGENCIA DE DESPLAZAMIENTO ONTOLÓGICO}

Es en el complejo escenario del Antropoceno/Capitaloceno, del que hemos puntualizado en algunas cuestiones, en el que se propone pensar el contexto de pandemia actual. La pregunta por la causa, en un sentido filosófico al tiempo que político, vuelve a poner la mirada en el modelo civilizatorio actual y su ontología dominante, al igual que con la noción de Capitaloceno. En este sentido, la novedad de la pandemia se inscribe como síntoma de un contexto más amplio y dramático. La pandemia es parte de una crisis civilizatoria que se viene gestando hace tiempo, lo que significa que, mientras se continúe avanzando sobre los ecosistemas y la explotación de los territorios (con sus vidas humanas y no-humanas), sin ningún tipo de límites y respeto, futuros virus y "super bacterias" surgirán.

La cotidianidad de nuestras vidas se vio atravesada por una experiencia común a nivel mundial. Un virus que afecta a todos los seres humanos y que nos puso bajo un régimen de aislamiento, como medida ante su rápida diseminación. Sin embargo, cabe aclarar que biológicamente el virus nos reconoce como partes a todos de una misma especie, pero las desigualdades creadas por el modelo de vida actual se refuerzan ante esta crisis sanitaria. 
Rev. Interd. em Cult.e Soc. (RICS), São Luís, v. 6, n. 2, p. 86-101, jul./dez. 2020

ISSN eletrônico: $2447-6498$

Las consecuencias de esta parálisis y freno abrupto no tardaron en difundirse en los medios de comunicación durante los primeros meses de esta pandemia. Entre las cuales, comenzaron a circular imágenes de la disminución de la polución aérea en las grandes metrópolis y de la contaminación de aguas, dada la baja de la quema de combustibles fósiles. Animales salvajes apareciendo en las ciudades con humanos recluidos en sus casas. Bajo estas impactantes imágenes, se recuperaba el mensaje de un mundo que está mejor sin nosotros, la Humanidad del Antropoceno. Esto, como hemos argumentado en las páginas anteriores, es problemático.

Sin embargo, lo que sucede es que el capitalismo global no dio tregua. En cuanto a las actividades extractivas como la minería y la explotación de hidrocarburos en los territorios, continuaron su curso. La frontera de la industria agropecuaria siguió expandiéndose, bajo el avance de la deforestación y los incendios intencionales a gran escala. En síntesis, la práctica de apropiación de las naturalezas, que Moore señala como gran innovación del capitalismo desde fines del siglo XV, no sintió la parálisis. .

El paradigma bélico bajo el cual la modernidad capitalista ha instaurado el dualismo Hombre/Naturaleza, se manifiesta también en una guerra declarada contra el virus. Esta lógica de guerra, instala el andamiaje institucional Estado-Ciencia-Capital, reactualizando el sesgo antropocéntrico de la ontología dualista. La Ciencia, refuerza su jerarquía epistémica, con el mando de las ciencias biológicas y médicas, son las que en primera fila deben contener al enemigo y crear las armas necesarias para vencerlo. Por su parte, las ciencias sociales se ocupan de cómo crear medidas paliativas y de control social, cómo continuar el normal funcionamiento de las viejas instituciones. Este es un tratamiento moderno del virus, es decir, bajo los marcos y las instituciones modernas, estamos ante elecciones dicotómicas y un exagerado antropocentrismo.

El propio modo de existencia no ha sido revisado y eso es lo más dramático. Este dossier nos convoca a pensar que el mundo post-pandemia estará lejos de haber "aprendido" algo de toda esta situación si no se revisan las raíces que comparten el Antropoceno/Capitaloceno y la crisis civilizatoria. Y las raíces son el modelo civilizatorio dominante y su ontología dualista y jerárquica. Todo ello conduce a la necesidad de vislumbrar otras opciones civilizatorias que comprendan a los humanos de manera relacional con el resto de los mundos no-humanos. Esto consiste en una mutación ontológica impostergable, hacia otras ontologías posdualistas negadas y excluidas por la dominante. 
Rev. Interd. em Cult. e Soc. (RICS), São Luís, v. 6, n. 2, p. 86-101, jul./dez. 2020

ISSN eletrônico: 2447-6498

En cierta forma la experiencia de la pandemia pone en evidencia la relacionalidad profunda del tejido de la vida, pero al mismo tiempo es la manifestación de la negación sistemática de esa relacionalidad por parte de la globalización capitalista. Es el empobrecimiento propio de una globalización neoliberal que declara la guerra contra los mundos relacionales, al reiterar y profundizar los intentos de consolidar un único mundo, definido por una única ontología (de la separación, del individuo, etc.). Esta ontología se plasma en el régimen de plantación actual y la cría industrial de animales, bajo la ficción de que eso que hacemos con el mundo no nos afectará. De este modo, entender la genealogía profunda del virus, implica tensionar las estructuras y los factores de larga duración que la incubaron. Desde diferentes análisis (RIBEIRO, 2020; WALLACE, 2020) se apunta a un origen común: el modelo industrial agroalimentario. Estos advierten que el sistema agroindustrial global está gestando las próximas pandemias, por lo que finalmente el control del Covid-19 (bajo la producción de una vacuna), no será más que una acción paliativa.

En el mundo post-pandemia pervivirá la alarma de la crisis civilizatoria actual en sus más diversas aristas. "En definitiva, el coronavirus emerge como síntoma de la expansión de los procesos de mercantilización hacia las últimas fronteras de la vida. La maquinaria agroindustrial está asfixiando la vida silvestre y la vida en sí. Estamos asistiendo a las últimas escenas del devenir plantación de la Tierra" (MACHADO ARÁOZ, 2020). Este devenir plantación del planeta es una modalidad más del Antropoceno/Capitaloceno, expresado con el término que utilizaba Haraway, Plantacionoceno. Este régimen de plantación que involucra una diversidad de factores, como semillas transgénicas con su combo de agrotóxicos, monocultivos, uniformización y simplificación de la producción y alimentación, así como la cría de animales bajo condiciones alarmantes, es todo ello una fábrica de pandemias.

\section{A MODO DE CIERRE NO CONCLUSIVO}

Dado que, como argumentamos, la ontología dualista, entre otras dinámicas de la globalización neoliberal, ha conducido a consecuencias nocivas que ponen en riesgo la continuidad de la vida en la tierra, consideramos que el enfoque posdualista y relacional responde de manera propositiva. En este sentido Vázquez reflexiona: "Pienso que la relacionalidad es la fuerza de esperanza, el principio ético y la fuerza de resistencia frente a un sistema que requiere de individualizar, de separar para dominar, que requiere de fracturar para dominar" (VÁZQUEZ y BARRERA, 2015, p. 87). De esta manera, la relacionalidad y los 
Rev. Interd. em Cult.e Soc. (RICS), São Luís, v. 6, n. 2, p. 86-101, jul./dez. 2020

ISSN eletrônico: $2447-6498$

mundos relacionales conforman una práctica ontológica política con fuertes potencialidades para construir una vida sustentable, a lo cual seguiremos apostando en un mundo postpandemia.

\section{REFERENCIAS}

ASAFU-ADJA et. al. (2015) "Un Manifiesto Ecomodernista”. Instituto Breakthrough. Trad.: Andrés Hoyos. Disponible en: http://www.ecomodernism.org/espanol.

BORSANI, María Eugenia (2014) "El encuentro con la decolonialidad desde este sur" en Borsani, María Eugenia (comp.); Ejercicios decolonizantes en este sur. Buenos Aires: Ed. del Signo y Center for Global Studies and the Humanities, Duke University.

(2017) "Devastación antropogénica y violencia racial" en Otros Logos. Revista de Estudios Críticos, CEAPEDI, Universidad Nacional del Comahue, $\mathrm{N}^{\circ} 8$.

CHAKRABARTY, Dipesh (2018) “Anthropocene Time", History and Theory 57, $\mathrm{n}^{\circ}$ 1, pp. 532.

(2009) “Clima e historia: cuatro tesis" en Pasajes, $\mathrm{N}^{\circ} 31$, pp. 51-69.

CRUTZEN, Paul J.; STOERMER, Eugene F. (2000) "The 'Anthropocene"” en Global Change Newsletter, $\mathrm{n}^{\circ} 41$, pp. 17-18.

DANOWSKI, Déborah; VIVEIROS DE CASTRO, Eduardo (2019) ¿Hay un mundo por venir? Buenos Aires: Caja Negra Editora.

DESCOLA, Philippe (2017) “Humano, demasiado humano?” en Desacatos, $\mathrm{n}^{\circ} 54$.

ESCOBAR, Arturo (2016) Autonomía y diseño: la realización de lo comunal. Popayán: Editorial Universidad del Cauca.

HARAWAY, Donna (2016) “Antropoceno, Capitaloceno, Plantacionoceno, Chthuluceno: generando relaciones de parentesco" en Revista Latinoamericana de Estudios Críticos Animales, Año III - Volumen I.

LANDER, Edgardo (2019) Crisis civilizatoria. Experiencias de los gobiernos progresistas y debates en la izquierda latinoamericana. Guadalajara: CALAS.

MACHADO ARÁOZ, Horacio (2020) "Pandemia: sintomatología del Capitaloceno" en Lobo Suelto!, 25 de abril de 2020. Disponible en; http://lobosuelto.com/capitaloceno-virusmachadoaraozl

MOORE, Jason (2019) "Capitaloceno y justicia planetaria" en Revista Herramienta, web n 27, diciembre 2019. 
(2017) "Entrevista a Jason Moore: Del Capitaloceno a una nueva política ontológica" en Ecología Política, n ${ }^{\circ} 53$. (2016) Anthropocene or Capitalocene? Oakland: PM Press.

RIBEIRO, Silvia (2020) "Las causas de la pandemia. No le echen la culpa al murciélago" Entrevista de Claudia Korol, en Página 12, 03 de abril de 2020. Disponible en: https://www.pagina12.com.ar/256569-no-le-echen-la-culpa-al-murcielago.

STENGERS, Isabelle (2017) En tiempos de catástrofes. Buenos Aires: Futuro Anterior / Ned Ediciones.

TRISCHLER, Helmuth (2017) "El Antropoceno, ¿un concepto geológico o cultural, o ambos?" en Desacatos, n 54 , pp. 40-57.

VÁZQUEZ, Rolando; BARRERA, Miriam (2015) “Aesthesis decolonial y los tiempos relacionales. Entrevista a Rolando Vázquez” en Calle 14, n 11, pp. 76-94.

WALLACE, Rob (2020) "La responsabilidad de la agroindustria en el Covid-19 y otras enfermedades virales", Entrevista de Pyaak Pabst, en Marx 21, 16 de marzo de 2020. Disponible en: https://marx21.net/2020/03/16/coronavirus-la-agroindustria-puede-provocarmillones-de-muertes/ 